"We look before and after, And pine for what is not;

Our sincerest laughter

With some pain is fraught;

Our sweetest songs are those which tell of Saddest thought."

(Nature.)

With reference to heredity especially (as too commonly understood), in the face of what has been brought forward, while it has undoubted significance with reference to certain constitutional diseases, it is, notwithstanding, amenable to the same organic forces as feebleness of constitution in general ; dependent more upon parental feebleness and unhealthful regimen in early life than upon specific tendency. The offspring of poorly nourished, dyspeptic parents, for illustration, are scarcely less liable to pulmonary consumption than the offspring of those affected with that disease; and the offspring of drunkards and of those who use narcotics to excess are well known to be fully as liable to insanity, epilepsy and idiocy as they are to inebriety. Indeed, hereditary feebleness of constitution is the prevailing "predisposition" to disease, and this, associated as it frequently is with inadequate nourishment and neglectful regimen during childhood, accounts in a great degree for the excessive mortality which obtains in infancy.

But in advocating more attention to personal regimen as the chief means of cultivating constitutional stamina and thus increasing the power of resistance to disease, which it is the purpose of this paper to urge, there should be no diversion from the effort to destroy the foci of disease germs and to maintain healthful surroundings. It should always be borne in mind, however, that the ability of the practical sanitarian to successfully cope with infectious disease-germs and their foci, and to maintain his own immunity, is the same as that of other persons: in proportion to the power of resistance, based upon constitutional and cherished stamina.

\section{WHEN SHOULD THE OBSTETRIC FOR- CEPS BE USED? AND WHAT FORM OF INSTRUMENT IS REQUIRED?}

Read in the Section of Obstetrics and Gynecology at the Fortieth Annual Meeting of the American Medical Association, held at Newport, $R$. $I$., June, 1889 .

BY WILLIAM S. STEWART, A.M., M.D., PROFESSOR OF OBSTETRICS AND CLINICAL GYNECOLOGY IN THE MEDICO-CHIRURGICAL COLLEGE PHILADEIPHIA, PA.

The question as to when the obstetric forceps should be used follows on the assumption that there are times when they are required. Taking for granted this necessity let us briefly refer to it, enumerating in the first place the circumstances and conditions which do not justify the application of the blades.

The forceps should never be used simply to gratify nervous patients, interfering nurses or meddlesome women, nor to save the time of a practitioner, busy or otherwise. The possibility and comparative ease of applying the blades within the partially dilated os is no indication that even the most careful use in such cases may not result in the rupturing of the cervix and other soft parts, exposing the patient to the immediate dangers from hæmorrhage, septicæmia and the various inflammatory conditions, and as well the possibility of life-long suffering.

The indications for the use of the obstetric forceps may be enumerated as follows :

I. Where speedy delivery is necessary in the interest of either mother or child; as in eclampsia, hæmorrhage, exhaustion, prolapse of the cord, etc. 2. Where the ordinary forces of labor are insufficient to overcome the obstacles to delivery ; as in narrowing or partial obstruction of the birth-canal within certain limits, uterine inertia, large fotal head, malpositions, and where the head is engaged in the pelvis and there has been no advance for some time, the "rebound" during the interval between the diminishing pains having ceased.

In addition it is of importance in all cases before applying the forceps to be assured of the existence of the following conditions: I. That the membranes are ruptured. 2. That there is complete dilatation of the os and retraction of the cervix. 3. Knowledge of the position of the presenting part. 4. Emptiness of the bladder and bowel.

What form of Obstetric forceps should be employed?

The general answer is to use the form best adapted to, the case if possible. It must be admitted, however, that each practitioner has acquired by repeated experiences a certain degree of skill in the use of his choice of instrument, notwithstanding its imperfections. But it is not my purpose to refer to the list of instruments which have been more or less in use since the time of Chamberlen's invention, either by condemning one or extolling another, but rather to call your attention to some mathematical principles which should be taken into account in the construction of the obstetric forceps.

It is a trite, but no less true saying that "necessity is often the mother of invention" with myself it has been the long felt necessity for certain unfulfilled requirements in the obstetric forceps in use that has led to investigations and experiments in this direction. My chief objection to the instruments in use has been the crossing of the handles, which, as we are all aware, necessitates the application of the right blade first in order that they may be locked. When the case is one of ordinary position of the head (first position, or left occipito-anterior) there is usually no difficulty in applying the blades in 
the regular order; but it has been my experience, as it has no doubt many times been yours, that when the head is in the second position (right occipito-anterior) or is jammed into the right side of the pelvis, after applying without difficulty the first or right blade of the instrument the introduction of the other was not possible without great risk of injury to mother and child. In every case that I recall, after removing both blades and reversing the order of their introduction no difficulty was encountered till recrossing in order to lock was found impracticable without equally great risks of inflicting injury. An instrument made with the crossed handles reversed would undoubtedly be suitable in these cases, but for ordinary purposes it would not avail.

After much thought and study on this subject, not taking into account the blades, but handles to which any form of blade could be attached, and admitting of the application of either blade first, the instrument which it is my privilege and honor to present for your inspection and consideration is the result. The improvement, as has been said, is in the handles alone, and it is to this that your attention is called.

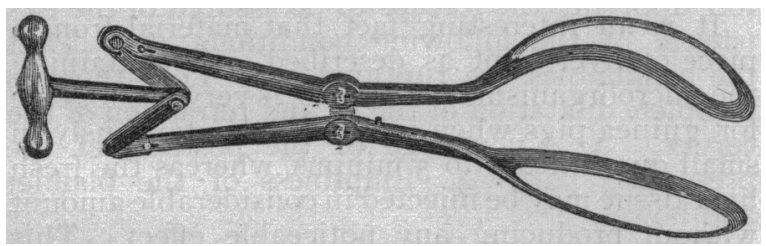

It was found necessary in constructing such an instrument, in order to avoid the difficulties arising from the crossing of the handles, to do away entirely with this form of handle, and return to the parallel handles improved by the addition of a second joint, and a hand piece so fitted that the necessary traction and compression can be made by a slight effort on the part of the operator.

The force employed is thus a conjoint one effected by means of a double lever, and is everywhere equal in amount to the resistance offered. The amount of traction necessary in the use of this instrument has been found by actual experience both on the manikin and the living subject to be very slight, and the compression just enough to keep the blades from slipping off the head, thus the amount of compression instead of being regulated by the grip of the operator as in the cross-handle instrument, is in every case controlled by the amount of resistance offered, so that in all ordinary cases there is little or no possibility of danger from this source. In certain cases, however, unusual force may be found necessary, and in order to avoid the risk of crushing the fotal head by the increased compression resulting the toggle joint has been constructed so as to limit the compression to a degree corresponding to that of the average instrument.

As an additional safeguard in malpositions and irregular curvatures of the pelvis, the principle joint is not a fixed one, but allows of slight forward and backward movements of the blades in order that there may be a better adaptation to the head as well as the pelvis; provision has also been made so that when with other instruments locking would not be possible, these handles may be secured and traction attempted, there being at the same time a slight vertical freedom of the blades to admit of the adjustment to the head becoming more perfect. When the locking can be made absolute from the first this motion does not exist. The advantages then secured in the locking are effected by means of a coned hub with a winged nut attached at the principal joint on the right arm of the instrument.

In twenty-six cases, ${ }^{1}$ all of which, undoubtedly, required instrumental delivery, $I$ have used these forceps with results which were indeed surprises, both on account of the facility with which they were applied-either blade first, the slight amount of traction required in all of the cases, and the entire absence of any disfigurement to the children or evidences that in a single instance the compression had been too great.

It is my conviction, gentlemen, that when the obstetric forceps is required the use of this instrument will be attended with fewer risks to the mother, greater safety to the child, and much less difficulty and anxiety to the accoucheur.

\section{RECENT RESEARCHES RELATING TO} THE ETIOLOGY OF YELLOW FEVER.

Read at the Meeting of the American Public Heallh Association in Brooklyn, N. Y., October 23, 1889.

BY GEORGE M. STERNBERG, MAJOR AND SURGEON U. S. A.

[Abstract for 'THE JourNaL.]

The investigation in which I am engaged under instructions from the President of the United States, and in pursuance of authority of an Act of Congress approved March 3, 1887, "making appropriations for sundry civil expenses of the government," is not yet completed. The cultures which I have brought with me from Havana will require further study, and extended comparative researches will be necessary before a definite conclusion can be reached as to the specific etiological relation of one or the other of the microorganisms which I have obtained from yellow fever cadavers, principally from the intestines.

Owing to the facts mentioned and the limited time at my disposal, I can only give a brief gen-

I Since reading the above I have applied the forceps, in all, the thirty-fourth time up to date, with the same degree of satisfaction thirty-fourth 